\title{
DRACUL ȘI AȘEZĂRILE LUI ÎN TOPONIMIA Carpaților Polonezi
}

\author{
AnNa Oczko \\ Universitatea Jagiellonă, Cracovia, Polonia
The devil and his geography in the toponymy of the Polish Carpathian Mountains

\begin{abstract}
The toponymy of the Polish Carpathian Mountains is rich in structures motivated by nomina propria and referring to evil forces. They are mainly based on four appellatives: Polish czart, szatan, diabet, and piekto. They usually refer to locations that are difficult to reach by people, e.g. steep slopes and mountain peaks, remote rocks, gorges, etc. Names of geographical objects are motivated by folk tales which allowed local populations to explain mysteries connected with places evoking horror. In these folk legends the devil reveals his three faces - destroyer, constructor, and guardian of treasures. The second category of motivations refers to toponyms whose natural forms are related to danger or activities of natural phenomena, e.g. strong winds. The last category of motivations is a result of rituals considered heretical by local populations.
\end{abstract}

Keywords: Carpathian toponymy, oronymy, devil, Polish language, onomastic motivation.

Dracul, un personaj omniprezent în cultura poloneză, a cărui imagine, pe parcursul secolelor întregi, rezulta din amestecul influențelor provenite din Europa Occidentală, Meridională și Orientală (Rożek 1993: 7), stârnea imaginația poporului care, la rândul lui, era înfricoșat de preoți cu viziunile apocaliptice ale Judecății de Apoi, ale cărturarilor pricepuți în teologie și ale celor care au greșit drumul, sacrificându-se științelor ocultistice. Toți aceștia aprofundau fenomenul Răului încercând, astfel, să-și asigure un profit fie de natură materială, fie de natură spirituală, care le-ar fi permis să îmblânzească viziunile înspăimântătoare ce rezultau din învățăturile biblice. Interesul acesta durează până în prezent, când dracul devine obiectul cercetării în numeroase domenii ale științei: teologie, etnografie, psihologie, literatură, lingvistică. Merită să menționăm și bogația culturii pop actuale, în care înfățișarea satanică a devenit fie obiectul unui cult, fie al unei distracții, fie al unui joc.

Dracul, care apare în folclorul polonez (Rożek 1993: 188) "to figlarny czorcik, (...) ale w sumie sympatyczne stworzenie” („este un drăcușor amuzant, puțin răutăcios, dar, în cele din urmă, o creatură simpatică” $)^{1}$, nu mai este o ființă distructivă,

1 Toate traducerile poloneze provin de la autoare. 
posedă și trăsături pozitive, reprezentând, totodată, puterile vitale legate de un ciclu vegetativ. Este un diavol „încreștinat”, adică aliatul omului care, luându-i sufletul, este însărcinat să-i slujească și să-i potolească dorințele. Cu diavolul, omul negociază, îi pune condiții și semnează pacte. Uneori, un simplu om apare mai isteț decât forțele iadului, iar un țăran prost, o femeie, precum și un șleahtiț viclean ca Domnul Twardowski², par că îl păcălesc pe Diavol, făcându-l prost. În cultura românească, imaginea dracului este una diferită: omul este sedus cu promisiuni deșarte, împins către păcat și, în cele din urmă, pierdut în iad. Totuși, diferența aceasta se explică prin faptul că lumea occidentală a epocii postmedievale, care a avut impact puternic asupra culturii poloneze, a părăsit contextul discursului iconografic privind păcatul originar, prezent în pictura exterioară a mănăstirilor moldovenești și aduce în prim-plan scena din ciclul căderii lui Adam, în care acesta semnează pactul cu diavolul. Acest motiv biblic, în vestul Europei, în secolul al XVI-lea, dă naștere lui Faust care și-a vândut sufletul diavolului în schimbul tinereții, cunoașterii și puterii magice (Pop-Cureșu 2013: 69-71). Lucian Blaga semnalează într-un pasaj din Despre gândirea magică că „Adam încheie zapisul cu Necuratul în cu totul alte împrejurări și din alte pricini decât Faust". Adevărata tragedie a lui Adam este că acesta iscălește contractul, fiindcă altfel nici nu ar fi putut să trăiască, îl semnează ca „ființa organică numită om vânzând astfel tot neamul omenesc. $\mathrm{O}$ asemenea variantă a legendei nu putea să se ivească și nici să prindă rădăcini decât în sufletul popular al răsăritului nostru" (Blaga 1941: 94-95, cf. Pop-Cureșu, 2013: 74). Pe de altă parte, și în spațiul polonez dracul întotdeauna l-a amenințat pe om, iar Biserica nu-i permitea niciodată să-l uite. Totuși, poveștile populare despre draci, care se relatau atât în căsuțele țărănești, cât și în casele burgheze, se aseamănă cu basmele unde Binele repurta o victorie asupra Răului. Se credea că Satana va cădea victimă rațiunii unui țăran sau, în special, istețimii unei femei ca în faimoasa Balada despre doamna Twardowska a lui Adam Mickiewicz. Asemenea povești, pline de „comicul satanic”, erau un soi de reacție față de sentimentul pericolului permanent, absolut, dar și abstract, proclamat de mediul ecleziastic.

Indiferent cum ar fi credințele populare privind imaginea dracului și rolul acestuia în cultura locală, el este prezent și în toponimie, deoarece la baza unor nomina propria stau frecvent lexeme legate de numele dracilor. Fenomenul se observă nu numai în Europa, ci și în alte părți ale lumii, unde se continuă tradiția creștină. Peste tot există locuri sau obiecte care nasc teroare și spaimă (Rutkiewicz-Hanczewska 2013: 103), de exemplu Muntele Beelzebub, din Alaska, Statele Unite (un caz izolat, neîntâlnit în oronimia europeană, care nu cuprinde denumiri motivate antroponimic, având la origine numele biblice ale demonilor ${ }^{3}$ ), Piatra Dracului din Hida, județul Sălaj, și din Bistrița, România, Pietra Demone din Monti Sabini, Italia sau din apropierea Coloniei, Germania. Conform credințelor populare, demult, diavolul a dus pietrele acestea pen-

\footnotetext{
2 În cultura și literatura poloneză, Domnul Twardowski este un personaj legendar care a iscălit pactul cu dracul.

3 În cărțile Noului Testament apar și celelalte nume ale Satanei: Lucifer și Belzebub (Di Nola 2000: 167).
} 
tru a distruge o mănăstire sau pentru a construi un zid, dar odată cu primele raze ale soarelui le-a lăsat să cadă, imprimând și urmele labelor sale pe bolovan. Diavolul are și așezările sale preferate: peșteri, stânci, vârfuri stâncoase, unde a putut să-și arate forțele sale magice sau, pur și simplu, locuri care, din cauza configurării reliefului, amintesc de prezența lui. Tot acolo își păzește invidios comoara ascunsă, fiind, totodată, gardian-ocrotitor al bogăției subterane (Di Nola 2000: 325). Astfel, atât coastele alpine, cât și cele ale Carpaților sunt pline de așezări diabolice, iată câteva exemple: Pizzo del Diavolon della Malgina (Vârful Dracului de Malgina), în provincia Bergamo, în Italia, Murata del Diavolo (Zidurile Dracului), în Munții Pettino și Arischia, Peștera Drăcoaia, în Munții Bihor, România.

Șirul nordic al Carpaților ${ }^{4}$ (Munții Bieszczady, Beskidy și Tatra), care se întinde pe teritoriul polonez, este bogat în toponime „drăcești”. Numele topografice sunt de obicei compuse, unde obiectul geografic fiind definit de un adjectiv derivat de la substantivul „diabeł”, cu toate că formele adjectivului prezente în sudul Poloniei sunt, de fapt, numai două: diabli și diabelski ${ }^{5}$, de ex. Diabla Góra, Diabelska Góra, Diable Skaty, Diabli Dót, Diabli Kamień (Rutkiewicz-Hanczewska 2013: 106). Un exemplu al numelui propriu derivat de la diabeł este Diablak - numele celui mai înalt vârf al muntelui Babia Góra, cea mai înaltă culme a munților Beskidy. În Tatra, deasupra Văii Lejowa, se înalță dealul Diabliniec, cu sufixul -iniec, tipic construcțiilor oronimice (cf. Szczeliniec, Jaroniec etc.). Există și o structură diminutivă Diabełek, un pas atipic sub coastele Wielka Królowa Kopa. Małgorzata Rutkiewicz Hanczewska (2013: 106) atrage atenția asupra unui fapt foarte interesant și anume: apelativul pol. diabet - un vechi împrumut din limba cehă veche având la origine cuvântul grec diábolos 'calomniator, defăimător' (Boryś 2006: 113) - este legat de de însușirile psihice ale răului, în timp ce un alt lexem slav czart, sinonim cu termenul grecesc, se referă la însușirile exterioare, întrucât czart ar fi provenit din forma paleoslavă a participiului * črtz, derivată de la verbul plsl. *čerti ( 1 pers. *čsra) 'a tăia' - apelativ ce trimite la imaginea unui drac schilodit sau care jupuiește scoarța unui copac (Boryś 2006: 91). Acest aspect este ilustrat de numele unui vârf din Beskid Śląski foarte cunoscut ca atracție turistică, Czantoria. Etimologia acestui toponim, propusă de Alexander Brükner este discutabilă, deși pe lângă celelalte explicații, mai ales populare ${ }^{6}$, pare probabilă. Lingvistul consideră că trecerea lui $r$ în $n$ rezultă din disimilarea populară Czartoryja < Czantoria, iar numele dealului înseamnă „pământul răscolit de cârtițe” 7 . Așadar, avem aici un exemplu de denumire metaforică: daunele făcute de cârtițe au fost evidente, astfel că aceste animale au fost bleste-

4 Corpul oronimelor analizate în lucrarea de față a fost extras din: hărți turistice, ghiduri turistice ale Munților Beskidy, situri online ale primăriilor, Paryscy, W. și Z., 2001. Wielka Encyklopedia Tatr, Kraków.

5 În nordul Poloniei, mai apare un alt derivat adjectival, diabelny: Diabelna Góra.

6 http://toninapisal.blogspot.com/2015/01/czantoria-pochodzenie-i-otaczajace-ja. html (accesat în 31 august 2017).

7 http://www.beskidzka24.pl/artykul,gorskie_szczyty_skad_te_nazwy_,28083.html (accesat în 31 august 2017). 
mate de localnici și comparate cu dracii (cf. Brückner 1996: 73). Totuși, numele Czart apare rar în toponimia Poloniei de Sud, se poate enumera doar câteva cazuri precum Czarcie Wrota (rom. Poarta Dracilor), în podișul Wyżyna Krakowsko-Częstochowska, pe drum înspre Valea Będkowska, lângă Cracovia. Tot în partea slovacă a Tatrei Mari, în Szatania Przetęcz (rom. Pasul Satanei), se înalță turnul numit Czarci Róg (rom. Cornul Dracului).

În vorbire, se remarcă utilizarea unui alt termen asociat imaginii diavolului, sza$\tan$ (rom. satan), un împrumut din limba cehă veche šatan cu origine latină sau greacă, cf. satanas 'dușman' (Boryś 2006: 594). Este interesant că în oronimia poloneză această denumire de fapt nu există. În Tatra Mare, în partea slovacă, unul dintre vârfuri, de peste două mii de metri altitudine, este numit Szatan (slov. Šatan), dând numele și celorlalte puncte ale masivului: Szatani Potok (rom. Pârâul Satanei), Dolinka Szatania (rom. Valea Satanei), Szatani Żleb (rom. Culoarul Satanei) și Szatania Przełęcz (rom. Pasul Satanei), iar în Tatra Occidentală, Slovacia, este cunoscută Szatanowa Polana (rom. Poiana Satanei).

Un alt termen polonez asociat cu prezența dracului, bogat reprezentat în toponimia montană, este piekto 'iad'. Totuși, trebuie relevat faptul că piekto are două semnificații: una biblică, definită de toate dicționarele contemporane ${ }^{8}$ (rom. iad, infern) și una arhaică, citată mai ales de dicționare etimologice: plsl. ${ }^{*} p_{b} k$ bl lo 'smoală' (Boryś 2006: 589). Pe tot teritoriul Poloniei, numele satelor Piekło sau Piekietko (forma diminutivală) se referă foarte des la cea de-a doua explicație, denumind locuri unde, pe vremuri, fie s-a produs smoală, fie s-au ars plantele (pajiști sau păduri) pentru a crea pământul agrar sau au avut loc incendii. În ceea ce privește punctele topografice de pe teritoriul montan, acestea, de obicei, își datorează numele forțelor înspăimântătoare ale naturii care amintesc de omniprezența malefică a dracului. Așadar, astfel de denumiri au fost date atât pentru vârfuri și culoare (ex. Piekło în Valea Kondratowa, Tatra), cât și pentru pârâuri (ex. Piekto în Gorce, Piekielny Potok, în Beskid Mały, Piekielnik - afluentul lui Czarny Dunajec) sau păduri (pădurea de pe pantele Grońului, Beskid Makowski).

\section{Motivația toponimică}

Motivarea toponimelor care se trag din numele dracilor nu este omogenă. Totuși, cel mai frecvent ele se sprijină pe legende și basme populare. În cultura poloneză, se observă faptul că pietrele dracului, de obicei stâncile solitare, de mărimi impresionante, care se află foarte des în apropierea unei biserici sau a unei mănăstiri, își datorează numele forțelor diabolice. Localnicii credeau că pietrele au fost aduse de Dracul care le-a scăpat acolo la auzul cântecului cocoșilor sau al unei cântări bisericești de la răsăritul soarelui. $\mathrm{Cu}$ acel pietroi, el voia să distrugă biserica sau un alt obiect important pentru oameni (Rożek 1993: 205). Conform legendei, acesta ar fi fost destinul mănăstirii

8 Według niektórych religii: miejsce kary, na którą skazane są potępione dusze zmarłych (în multe religii: loc în care sufletele păcătoșilor sunt supuse la chinuri veșnice pentru a-și ispăși păcatele din timpul vieții) https://sjp.pwn.pl/szukaj/piek\%C5\%82o.html (accesat în 2 septembrie 2017). 
Ordinului Cistercian de lângă Szczyrzyc, dacă nu ar fi intervenit Maica Domnului. La Krynica Zdrój, dracii voiau să astupe cu piatra imensă desprinsă din Munții Tatra un izvor înviorător. Din fericire, le-a întrerupt inițiativa cântecul cocoșilor și au scăpat-o pe coasta Jaworzynei Krynicka, în Beskid Sądecki.

Într-un alt tip de legendă, de exemplu în cazul muntelui Diablak, în Beskid Żywiecki, apare Diavolul „constructor”. Conform contractului semnat cu un haiduc, diavolul a trebuit să-i construiască acestuia cetatea pe cel mai înalt vârf. Dimineața, la cântatul cocoșilor, au fost pedepsiți amândoi: dracul nu a reușit să termine cetatea, iar tâlharul și-a pierdut viața îngropat sub pietrele prăvălite. Până astăzi, noaptea se pot auzi acolo țipetele haiducului înmormântat în sediul lui dărâmat.

În Tatra circulă încă o legendă care explică numele vârfului Szatan și al turnului Diablowina ${ }^{9}$. Acolo, diavolul păzește pietrele prețioase ascunse în Szatański Żleb (rom. Culoarul Satanei). În secolul al XVIII-lea, au fost atestate în documente escapadele căutătorilor de comori, care căutau avuții la poalele muntelui. Poate și pietrele care cădeau de sus au produs sentimetul că dracii își păzesc bogația (Paryscy 1995: 1182), dorind, astfel, să-i înspăimânte pe intruși. Totuși, odată un cioban isteț, după ce a iscălit pactul „sufletul în schimbul bogăției”, a reușit să-l păcălească pe diavol păstrându-și sufletul, iar acesta i-a arătat drumul spre comoară.

Asemenea stâncilor care formează o poartă naturală (ex. Czarcie Wrota), și podurile naturale de stâncă, cum ar fi cel de pe lângă Ciężkowice (de fapt, singura formațiune de acest gen din Beskidy), au fost considerate de către localnici drept poarta reședinței dracilor. Acolo, pe podul numit Diable Boisko (rom. aria dracilor), spune legenda, dracii se odihneau și se destrăbălau ${ }^{10}$.

Toponimele care au la bază numele dracului pot fi motivate de formele de relief care amintesc de un pericol satanic. De obicei, acestea sunt niște prăpastii, unde cad pietre, ori pante abrupte și alunecoase - de ex. Diabliniec, în Velea Lejowa. În această categorie includem și denumirile motivate de fenomene naturale. Vânturile puternice sunt, la rândul lor, asociate cu forțele necurate, iar locurile bătute de acestea poartă numele dracului: pasul Diabełek (menționat deja mai sus) unde în timpul vijeliilor „bate cu pietrișul în ochi ca dracu”. Tot în Tatra, o mică depresiune în Valea Kondratowa se numește Piekło sau Piekietko datorită vânturilor anevoioase. De forțe satanice se leagă și culoarea pietrei pe care o are stânca solitară, de pildă cea de lângă localitatea Ciężkowice Piekietko - roșie „ca și când ar fi adusă din iad”.

Denumirile a două culmi, una aflată în Gorce, celălaltă în Beskid Wyspowy, sunt motivate nu de ritualurile ocultistice, ci de cele creștine! În sec. al XVI-lea, pe vârful

9 Ambele obiecte geografice se află în partea slovacă a munților. S-a remarcat faptul că, în timp ce muntenii au început să denumească anumite obiecte în Tatra, munții constituiau un spatiu comun, împărțit nu între state diferite, ci mai degrabă între ciobani, proprietari de pășuni, care posedau dreptul de a duce oi la păscut, cf. Hala Gąsienicowa, ori familii boierești, de ex. Dolina Mięguszowiecka (Mengusova).

10 Gmina Ciężkowice, http://www.ciezkowice.pl/pl/00210,pomniki_przyrody (accesat în 28 august 2017). 
muntelui Piekło (rom. iad) se adunau pentru rugăciune frații unitarieni ${ }^{11}$. Localnicii suspectându-i de contacte cu Satana, au denumit locul adunării acestora „Iad” (Gacek 2012: 22).

În poloneză, imaginea dracului este redată prin mai mulți termeni, în afară de cei prezenți în oronimie, diabet, sporadic czart, precum bies sau rokita, cu toate că aceștia din urmă nu au fost folosite ca bază a toponimelor în graiurile muntenești din sudul Poloniei (cf. Rutkiewicz-Hanczewska 2013: 110). Celelalte nume al dracului, existente în vocabularul bogat al tradiției poloneze, pokuśnik, zły, czarny, djebot, întâlnite în graiurile din Polonia Mică, nu au fost întrebuințate în procesul de denominație.

Oronimele au la bază, în general, patru apelative referitoare la puterile necurate: czart, szatan, diabet și piekło. Ultimele două sunt cel mai des reprezentate în oronimia poloneză, iar szatan este caracteristic pentru denumirile din munții Tatra, din partea slovacă. În ceea ce privește structura toponimelor, acestea sunt create cu ajutorul sufixelor -ak (Diablak),-iniec (Diabliniec), -nik (Pikielnik) ori conțin forme diminutivale: Piekietko, Diabetek. Designantele oronimelor analitice sunt caracteristice reliefului montan, însă apar și alte apelative, precum boisko (rom. arie) sau róg (rom. corn). Totuși, sensul lor este legat, metaforic, de relief. Denumirea obiectelor cu epitete ce trimit la imaginea dracului este adesea motivată de numeroase legende populare datorită cărora oamenii explicau prezența unor locuri înspăimântătoare. În legendele acestea, Dracul înfățișează trei fețe, una de distrugător, una de constructor și una de paznic-ocrotitor. A doua categorie de motivare o constituie toponimele ale căror forme fac trimitere la un pericol serios, precum pantele abrupte (Diabliniec) ori sunt legate de fenomene naturale, precum vânturile puternice (Piekto, Valea Kondratowa). Ultima categorie, puțin prezentată, este legată de ritualuri, considerate de către comunitățile medievale drept eretice.

\section{Bibliografie}

Boryś, W. 2006. Stownik etymologiczny języka polskiego. Kraków: Wydawnictwo Literackie. Brückner, A. 1996. Stownik etymologiczny jezyka polskiego. Warszawa: Wiedza Powszechna.

Di Nola, A. M. 2000. Diabet. Kraków: Universitas.

Gacek, D. 2012. Beskid Wyspowy. Pruszków: Rewasz.

Paryscy, Z. i W. 1995. Wielka encyklopedia tatrzańska. Poronin:Wydawnictwo Górskie.

Pop-Cureşu, I. 2013. Magie şi vrăjitorie în cultura română. Bucureşti: Cartea Românească.

Rożek, M. 1993. Diabet w kulturze polskiej. Kraków: Wydawnictwo Naukowe PWN.

Rutkiewicz-Hanczewska, M. 2013. Diabeł i jego imiona w toponimii wielkopolskiej i małopolskiej. În Cum reverentia, gratia, amicitia, J. Migdał, A. Piotrowska-Wojaczyk (eds.), 103-110. Poznań: Wydawnictwo Rys.

Słomski, W.1997. Polscy Arianie. Warszawa: Mix.

11 Unitarianismul, în afară de luteranism și anglicism, este unul dintre curentele principale ale Marii Reforme. În Polonia în XVI și XVII, pe plan social, unitarienii polonezi proclamau programul de reconstruire a societății și revendicau abolirea clăcii, ceea ce nu a putut să fie aprobat nici de autoritățile de stat, nici de cercurile bisericești. În 1658, cu decizia Senatului Republicii, Frații Polonezi au fost siliți să părăsească Polonia. Unii exilați și-au găsit adăpostul în Transilvania (Słomski 1997: 11, 31). 